REVISTA DE DERECHO UNED, NÚM. 14, 2014

\title{
ESTABLECIMIENTO DE SIMBOLOGÍA RELIGIOSA ESTÁTICA EN ESPACIOS PÚBLICOS SANITARIOS
}

\author{
ESTABLISHING RELIGIOUS STATIC SYMBOLS IN SANITARY \\ PUBLIC SPACES
}

Jacinto J. Marabel Matos

Asesor Jurídico. Consejo Consultivo de Extremadura

Resumen: El presente artículo completa la aproximación dedicada a los símbolos religiosos presentes en espacios públicos sanitarios, anteriormente publicado y en relación con el derecho de libertad religiosa del artículo $16 \mathrm{CE}$. En este caso, las aportaciones doctrinales a la jurisprudencia referida al establecimiento de simbología religiosa estática en el ámbito público, ponen de manifiesto la importancia de resolver estas cuestiones, una vez más, en base al principio de tolerancia.

Palabras clave: libertad religiosa; símbolos estáticos; servicios sanitarios.

Abstract: This article completes the approach dedicated to religious symbols in public sanitary spaces, previously published and relating the right to religious liberty of article $16 \mathrm{CE}$. In this case, the doctrinal contribution to jurisprudence concerning to the establishment of static religious symbols in the public areas, shows the importance of resolve these issues, over again, based on the principle of tolerance.

Key words: religious liberty; static symbols; sanitary services.

Recepción original: 20/01/2014

Aceptación original: 26/02/2014

(C) UNED. Revista de Derecho UNED, núm. 14, 2014 
Sumario: I. Introducción. II. Interpretación jurisprudencial del Derecho a la Libertad Religiosa frente a simbología estática en recintos y dependencias sanitarias públicas. III. Conclusiones.

\section{INTRODUCCIÓN}

En este trabajo nos aproximaremos al tratamiento jurisprudencial otorgado a los elementos estáticos, estables o trasladables, permanentes o alterables, con significado esencialmente de religioso presentes en los espacios públicos hospitalarios o sanitarios asistenciales.

Es de destacar que a su vez, el área, recinto o compartimento de implementación de las políticas públicas sanitarias se ha convertido en modelo de pluralidad religiosa. En consecuencia, la multiculturalidad reproduce y aumenta, a semejanza de la casuística derivada de la iconología dinámica, las interpretaciones en torno a la determinación y alcance del carácter del símbolo representado.

Este es el principal argumento que esgrimen quienes justifican la secularización en el imaginario público y vía tradición, de todos aquellos símbolos que en algún momento histórico tuvieron transcendencia religiosa, de conformidad con la interpretativa que tiene su fundamento en la STC 34/2011, de 28 de marzo, cuando expone que: «naturalmente, la configuración de estos signos de identidad puede obedecer a múltiples factores y cuando una religión es mayoritaria en una sociedad sus símbolos comparten la historia politica y cultural de ésta, lo que origina que no pocos elementos representativos de los entes territoriales, corporaciones e instituciones públicas tengan una connotación religiosa. Esta es la razón por la que símbolos y atributos propios del Cristianismo figuran insertos en nuestro escudo nacional, en los de las banderas de varias Comunidades Autónomas y en los de numerosas provincias, ciudades y poblaciones; asimismo, el nombre de múltiples municipios e instituciones públicas trae causa de personas o hechos vinculados a la religión cristiana; y en variadas festividades, conmemoraciones o actuaciones institucionales resulta reconocible su procedencia religiosa».

Sin embargo, el razonamiento se antoja engañoso, puesto que virtud precisamente de la identidad confesional de este país, a través de la práctica o la costumbre como pretende esta corriente, no puede 
negarse el carácter religioso de un crucifijo o un icono mariano en la entrada o zonas comunes de un hospital. Mientras que, en sentido contrario, resulta indudable que la propia cruz adquiere naturaleza secular en la fachada de una farmacia o como logotipo del servicio sanitario, en los mismos espacios públicos del recinto ${ }^{1}$.

Efectivamente, más allá de otorgar carta de naturaleza jurídica a un sistema de creencias, de pautas de conductas o códigos morales, como afirma MARTÍN-RETORTILLO, consideramos que la resolución a los problemas derivados de las controversias suscitadas con el establecimiento de símbolos estáticos religiosos en nuestros hospitales públicos, quedan reducidos hoy en día, con las prudentes salvedades, a meras cuestiones administrativas ${ }^{2}$.

La manifestación del derecho a la libertad religiosa en el ámbito sanitario, lugar de encuentro multicultural como se ha dicho, resulta en la actualidad el paradigma de estas cuestiones de gestión cuasiadministrativa que fueron señalas por CALLAHAN en su conocido estudio sobre los fines de la medicina ${ }^{3}$.

${ }^{1}$ Los símbolos nunca son inocentes. A título de ejemplo, podemos recodar que en 1999 fue inaugurado en los Emiratos Árabes Unidos el único hotel con siete estrellas del mundo: el Burj Al Arab, la Torre de los Árabes. Llamado a ser el símbolo de Dubai, su proyecto fue encomendado al estudio de Thomas Willis Wright, quien diseñó un edificio con forma de dhow, una embarcación tradicional del país. A doscientos metros de altura y proyectándose otros treinta metros a cada lado del cuerpo central se sitúa el restaurante Al Muntaha, efectivamente «el más alto» en su traducción literal. En breve tiempo se convirtió en icono del lugar, multiplicándose hasta en las matrículas de los vehículos la vista que ofrecía el edificio desde el mar, con la ciudad al fondo. Pasado un tiempo, alguien reparó en que esa representación era, ni más ni menos, que una inmensa cruz latina implantada a pocos kilómetros de La Meca. Desde entonces, es difícil encontrar una reproducción de esta vista, habiendo sido reemplazada por la imagen lateral, realizada desde la playa, del hotel más lujoso del mundo.

${ }^{2}$ La licencia reduccionista ha de ser interpretada con la mayor de las cautelas, puesto que resultan incuestionables las dificultades que presentan ciertos conflictos penales o constitucionales e, incluso de técnica legislativa. No obstante, estamos de acuerdo en que un notable conjunto de tensiones se reducen a problemas administrativos de mayor o menor entidad. MARTín-RETORTILLO BAQUER, Lorenzo. La afirmación de la libertad religiosa en Europa: de guerras de religión a meras cuestiones administrativas. Civitas. Pamplona, 2007; p. 91.

${ }^{3}$ Los cambios radicales evidenciados por las ciencias biomédicas en las últimas décadas del siglo pasado, pusieron de manifiesto una gran preocupación acerca del futuro de la asistencia sanitaria que obligaban a reformular los principios de la ética médica. Este fue el origen del proyecto Goals of Medicine realizado por el prestigioso centro de investigación bioética Hastings Center de Nueva York. En el año 1993 reunió a un amplio equipo de expertos de catorce países, entre ellos España, con el objetivo de establecer y desarrollar un ambicioso estudio sobre los fines de la medicina moderna cuyas conclusiones fueron reunidas en una obra de referencia desde enton- 
Sin embargo, y aunque no resulta posible abordar estos problemas bajo parámetros de gestión técnica-administrativa sin tener en cuenta las premisas, en la mayoría de los casos colisión de derechos fundamentales vinculados a la libertad religiosa, que subyacen en su origen, erróneamente se solventa el debate sustanciándose en el mejor de los casos mediante reformas presupuestarias o de personal ${ }^{4}$.

Con frecuencia, la acción de los gestores públicos posterga la resolución de este tipo de conflictos en sede judicial, en menoscabo de los principios de celeridad y eficacia que deben presidir la actuación administrativa y en manifiesto perjuicio del interés de los ciudadanos, cuando, como ya se expuso en nuestro trabajo precedente ${ }^{5}$, su función debe ir encaminada "a garantizar el orden público, la paz, y la tolerancia religiosa en una sociedad democrática... y considera la obligación del Estado es asegurar la tolerancia que los grupos que compiten entre sí. Por tanto, el papel de las autoridades en tales circunstancias no es eliminar la causa de la tensión eliminando el pluralismo, sino garantizar que los grupos de oposición se toleren mutuamente.

El pluralismo, la tolerancia y el espíritu de apertura son características de una sociedad democrática. A pesar de que en ocasiones subordina los intereses individuales a los de un grupo, la democracia no se limita a apoyar a la mayoría, sino a establecer un equilibrio que debe lograrse para garantizar el trato justo a las personas pertenecientes a minorías y evita cualquier abuso de posición dominante» ${ }^{6}$.

\section{INTERPRETACIÓN JURISPRUDENCIAL DEL DERECHO A LA LIBERTAD RELIGIOSA FRENTE A SIMBOLOGÍA ESTÁTICA EN RECINTOS Y DEPENDENCIAS SANITARIAS PÚBLICAS}

Resulta interesante comenzar este recorrido por la jurisprudencia relativa a la exposición de simbología estática religiosa en espacios

ces. Callahan, Daniel, Hanson, Mark J. (Coords.) The forgotten issues in Earth care reform. Universidad de Georgetown. Washington, 1999.

${ }^{4}$ Como se ha llegado a afirmar, "el discurso reformista suele estar dominado por debates acerca del papel del mercado, la privatización, la existencia o carencia de incentivos, el control del gasto y el análisis coste-beneficio, los métodos de deducciones y pagos compartidos, la variedad de planes presupuestarios y organizativos y las ventajas y desventajas de la centralización y la descentralización». CALLAHAN, Daniel. "Los fines de la medicina». Cuadernos de la fundación Víctor Grífols i Lucas, n. ${ }^{\circ}$ 11, Barcelona. 2005; pp. 16-17.

${ }^{5}$ Marabel Matos, Jacinto Jesús. El uso de simbología religiosa dinámica en espacios públicos sanitarios. Revista de Derecho UNED, n. ${ }^{\circ} 12$, 20013; pp. 413-437.

${ }^{6}$ STEDH, Caso Leyla Sahin contra Turquía, de 10 de noviembre de 2005. 
públicos sanitarios, a partir de los más recientes pronunciamientos de los tribunales a fin de evidenciar en sus conclusiones la actual línea interpretativa.

En este sentido, debemos partir de la STSJ de Cataluña 789/2012, de 27 de junio, en la que se desestimaron las pretensiones de la reclamante, médico del Instituto Catalán de Salud, que fue adscrita a una clínica privada concertada para prestar actividad asistencial pública. Como quiera que la misma era titularidad de una congregación religiosa, el uso de símbolos era patente en las instalaciones. La Administración, tras las reiteradas quejas elevadas por la interesada, retiró los menos conflictivos de ellos, si bien mantuvo, entre otros, los expuestos en la zona de gestión integrada de atención urgente y continuada, al considerar que la decisión última competía a la entidad religiosa titular del centro.

En el recurso se fundamentaba que muchos de los pacientes que acudían a recibir asistencia, "padecen enfermedades de cierta gravedad (y) quedan situados psicológicamente en una situación de fragilidad, debilidad y vulnerabilidad que puede propiciar un acercamiento abusivo hacia una determinada religión ${ }^{7}$. Es decir, el servicio se prestaba bajo un régimen de especial sujeción que haría especialmente vulnerable a sus usuarios frente a la presencia de imágenes religiosas, tales como crucifijos.

En cuanto al significado primordial de éste, la jurisprudencia es clara al respecto, pues ya la STS 688/1993, de 25 marzo, en la que se desestimaba un presunto delito de profanación en ofensa de los sentimientos religiosos, tras la emisión de un video musical en el que aparecía un crucificado con cabeza de carnero, determinó el carácter sagrado del crucifijo. En sus fundamentos se razonaba que «atendiendo a los dogmas y a los ritos de las distintas religiones... (y) concretándose a la Religión Católica, es incuestionable que, como se dice acerta-

${ }^{7}$ La apelante, conocida como «la doctora crucifijo» por sus continuas reivindicaciones al respecto, solicitaba el traslado a otro centro sanitario público alegando objeción de conciencia frente al ideario de la institución, enfrentada en cuanto a planteamientos bioéticos, prevención de enfermedades sexuales y políticas de planificación familiar. El tribunal, haciendo suyos los errados fundamentos del letrado de la Administración, desestimó sus pretensiones al no estar tipificadas en el derecho a la objeción de conciencia, de configuración legal señala equivocadamente y, abundando en el despropósito, tampoco le reconoce legitimación activa para invocarlo, puesto que en todo caso serían los pacientes los titulares del presunto derecho conculcado. 
damente en el motivo, el Crucifijo es para la Religión Cristiana quizá la cosa sagrada por excelencia después de la eucaristía».

En la más reciente sentencia del Juzgado de lo Penal n. ${ }^{\circ} 8$ de Madrid, 235/2012 de 8 junio, se concluía así mismo la inexistencia de delito contra los sentimientos religiosos, tras la polémica desatada a raíz de la emisión de un programa de televisión donde se cocinaba un crucifijo, sin perjuicio de calificar el mismo, según fundamentaba el pronunciamiento, de «símbolo de una creencia» 9 .

No obstante, debe advertirse que cuando hablamos de simbología estática no sólo debemos representarnos su carácter tangible, sino el inmaterial. En la citada STC 34/2011, de 28 de marzo, se razona que, "naturalmente, la configuración de estos signos de identidad puede obedecer a múltiples factores y cuando una religión es mayoritaria en una sociedad sus símbolos comparten la historia política y cultural de ésta, lo que origina que no pocos elementos representativos de los entes territoriales, corporaciones e instituciones públicas tengan una connotación religiosa. Esta es la razón por la que símbolos y atributos propios del Cristianismo figuran insertos en nuestro escudo nacional, en los de las banderas de varias Comunidades Autónomas y en los de numerosas provincias, ciudades y poblaciones; asimismo, el nombre de múltiples municipios e instituciones públicas trae causa de personas o hechos vinculados a la religión cristiana; $y$ en variadas festividades, conmemoraciones o actuaciones institucionales resulta reconocible su procedencia religiosa».

En la también mencionada STSJ de Castilla y León 3250/2009, de 14 de diciembre, se argumenta así mismo que «en relación con las manifestaciones públicas de un determinado ejercicio religioso (vgr. las procesiones de Semana Santa) también pueden surgir conflictos si un tercero rechaza su paso por su calle, si entiende que los fondos públicos no deben mantener semejantes manifestaciones confesionales...etc. Con

${ }^{8}$ La pretensión de obviedad, tuvo su reflejo normativo, entre otros y a título de mero ejemplo, en la Orden de 3 de noviembre de 1993 por la que se establece el currículo del área de Religión Católica en la Educación Infantil, y se le asigna un tiempo específico en la jornada escolar, se determina, que son símbolos cristianos «el crucifijo, la imagen de Jesús y María, el Niño Jesús, el Belén». BOE n. . 270, de 11 de noviembre de 1993.

${ }^{9}$ Juzgado de lo Penal n. ${ }^{\circ} 8$ de Madrid, 235/2012 de 8 junio, de conformidad con los razonamientos contenidos en las anteriores STS 668/1993 de 25 de marzo, citada; SAP de Sevilla 553/2004 de 7 de junio, en la que se absolvió al acusado que exhibió una imagen de la Virgen María junto a los genitales de un varón; y SAP de Valladolid $367 / 2005$ de 21 de octubre, en la que igualmente absolvió al acusado de exhibir, en plena Semana Santa y en el recorrido de una procesión, una pancarta con la imagen de la Virgen María y de Jesús en la que constaba una leyenda denigratoria. 
todo lo expuesto se quiere significar que un posicionamiento de laicismo maximalista supone una confrontación de derechos temporal y objetivamente ilimitada. Correlativamente, y por idénticas razones, una consideración desproporcionada del hecho religioso o de una o varias religiones supondrá también una confrontación de derechos temporal y objetivamente ilimitada. Por tanto, y como se avanzó, sólo mediante las limitaciones recíprocas de los derechos de todos se podrá hallar un marco necesario de convivencia».

La advocación religiosa, por tanto, no quebranta el principio de neutralidad de los poderes públicos. Es posible designar un centro sanitario bajo la tutela, protección o patrocinio de la divinidad o de los santos que la Administración decida consensuar y, en este sentido, resulta igualmente conforme al art. 16.3 CE la presencia de imágenes o figuras religiosas en los emblemas, logotipos o distintivos de hospitales y servicios sanitarios públicos, pues así fue reconocido, respecto al escudo de la Universidad de Valencia, en la STC 130/1991 de 6 de junio. En la misma, se consideró que la imagen de la Virgen de la Sapiencia que aparece en la parte central superior de dicho emblema, no contradice valores, bienes o intereses constitucionalmente tutelados, ni vulnera precepto legal alguno.

La decisión de alterar o modificar en un determinado sentido la simbología representativa de la institución corresponde a la Administración titular, en este caso, pudiendo resolver conforme a criterios de oportunidad o conveniencia, libremente valorados y decididos, sobre la simbología que mejor «la identifique o desempeñe de manera más oportuna o conveniente la función integradora o representativa que todo simbolo comporta o, lisa y llanamente, satisface o responde mejor a las sensibilidades y preferencias de diversa indole de quienes con su voto contribuyeron a la aprobación de los nuevos elementos representativos» ${ }^{10}$.

En similares términos concluye la citada STC 34/2011, de 28 de marzo, que desestima el recurso de inconstitucionalidad por presunta vulneración del derecho a la libertad religiosa, en su vertiente objetiva

${ }^{10}$ La STC 130/1991, de 6 de junio, establecía que en virtud del principio de autonomía universitaria, a través de la decisión mayoritaria de sus órganos de gobierno, la universidad valenciana podía adoptar su escudo, sello o símbolo de identidad y representación que determinase, «las evidencias históricas y las razones heráldicas no bastan, sin más, para menoscabar el derecho fundamental de autonomía universitaria ni, por ello mismo, para sustituir los símbolos libre y voluntariamente decididos por el Claustro Constituyente por otros que como los propuestos por la minoría disconforme, seguramente serían igual de lícitos y respetables, sólo que no han sido los mayoritariamente votados». 
y subjetiva, presentado por un letrado del Colegio de Abogados de Sevilla, en tanto sus estatutos reconocen como Patrona a la Virgen de la Inmaculada Concepción. Así, declara que «la posibilidad de que la corporación asuma signos de identidad que, desprovistos de una significación religiosa incompatible con el art. 16 CE, fueran en su origen propios de una u otra confesión o de ninguna, es algo que sólo a la corporación corresponde decidir democráticamente (art. $36 \mathrm{CE}$ ), considerando cuáles son las señas de identidad que de forma más oportuna o conveniente cumplen la función integradora o representativa buscada, o lisa y llanamente, satisface o responde mejor a las sensibilidades y preferencias de diversa indole de quienes con su voto mayoritario contribuyan a la aprobación de los elementos representativos de la institución; y que, en tanto se configuren como tradiciones, han de gozar de la protección pretendida por el preámbulo de nuestra Constitución».

La presencia de símbolos físicos también es admisible en determinados casos. En nuestro país resulta común en multitud de lugares públicos la presencia de símbolos estáticos de considerable relevancia, establecidos, precisamente, para resultar visibles a cierta distancia.

De este modo se constata, en los mismos recintos hospitalarios o en sus inmediaciones, la existencia de crucifijos, monumentos o estatuas representativas de figuras religiosas, cuyo mantenimiento, pese a ser manifestación de pasados regímenes confesionales, no puede entenderse como representativa de posturas de intolerancia hacia el no creyente.

La jurisprudencia ha resuelto los conflictos surgidos a raíz de la solicitud de retirada de este tipo de símbolos huyendo, precisamente, de posturas maximalistas, mientras que la doctrina tampoco ha planteado mayores objeciones, admitiendo la presencia de simbología estática en parques o recintos públicos, donde no existe régimen de sujeción y el condicionamiento o lesión de los derechos fundamentales, por tanto, es más débil ${ }^{11}$.

Las SSTSJ de Madrid 405/2011, de 20 de mayo, y de Valencia 648/2011 de 6 septiembre, desestimaron las peticiones de retirada de sendas cruces en los cerros de Monteagudo y de la Muela, en Murcia y en Orihuela, respectivamente, concluyendo en idénticos términos que «la neutralidad e imparcialidad del Estado exigida por el art. 16.3 CE no es en forma alguna incompatible con la presencia de símbolos religiosos en lugares públicos que como el presente no son sino expre-

${ }^{11}$ CaÑamares ArRiBas, Santiago. «Los símbolos religiosos en el espacio público. Entre la amenaza real y la mera sospecha». El Cronista del Estado Social y Democrático de Derecho, n. ${ }^{\circ}$ 20. Iustel, 2010; p. 67. 
sión de la historia y cultura de nuestro país (al margen lógicamente de las consideraciones que deban merecer sus valores artísticos o estéticos) que inevitablemente está cargada de elementos religiosos e ideológicos perfectamente compatibles con el principio de laicidad positiva exigido por la Constitución Española y así, si conforme a la sentencia del TEDH la muestra de símbolos religiosos en aulas de educación es compatible con los derechos de libertad religiosa en sus vertientes positiva y negativa, con mayor razón lo será en espacios en los que en principio no se desarrolla una actuación del Estado más allá del mantenimiento en su caso de un patrimonio histórico, artístico o cultural preexistente.

Tras concretar la tradición, ascendencia e historia especialmente cristiana de nuestro país, lo que reconoce la Constitución Española mencionando expresamente a la Iglesia Católica al lado de otras confesiones, expone la variedad de circunstancias en las que se pone de manifiesto, nombres, festividades, ritos religiosos, procesiones religiosas ante las cuales una pretensión de supresión supondría una confrontación de derechos temporal y objetivamente ilimitada, por lo que sólo mediante las limitaciones recíprocas de los derechos de todos se podrá hallar un marco necesario de convivencia».

La doctrina, que también resulta pacífica respecto a aquellos elementos permanentes que, unidos de una manera inescindible con el conjunto del edificio, su segregación produjera detrimento del mismo $^{12}$, no lo es tanto en cuanto a los iconos trasladables ${ }^{13}$. En nuestra opinión las habitaciones de los enfermos, consultas, quirófanos, pasillos, escaleras, recibidores y en general, cualquier zona común y pública del recinto hospitalario debe quedar expedita de objetos religiosos movibles; sin perjuicio de los introducidos por los propios pacientes durante su estancia y que, por lo común, suelen amparar su espacio más inmediato.

12 Alenda Salinas, Manuel, Pineda Marcos, Matilde. «La manifestación de religiosidad como motivo de conflictividad». Cuadernos de Integración Europea n. ${ }^{\circ}$ 7. Fundación General de la Universidad de Valencia, 2006.

${ }^{13}$ Fuera de este supuesto, para algunos autores, la presencia de simbología estática ha de reputarse contraria a los principios constitucionales: «en primer término, porque dicha presencia impregna de su significado a cuantas personas se encuentren en el recinto público, sin permitir diferenciación alguna para las personas que profesen otras creencias o convicciones a la simbolizada; en segundo lugar, porque supone una inequívoca voluntad del Estado de poner a la religión simbolizada en centro de la vida pública, como verdad absoluta, sin el respeto debido al papel que otras experiencias religiosas o filosóficas desempeñan en la sociedad; $y$, en tercer lugar, porque supone una adhesión de los propios centros públicos a una determinada y concreta cosmovisión religiosa, produciéndose una confusión entre funciones estatales y religiosas que resulta contraria al principio de laicidad». Contreras Mazarío, José María, Celador ANGón, Óscar. «Laicidad, manifestaciones religiosas e instituciones públicas». Documentos de trabajo, n. ${ }^{\circ}$ 124, Fundación Alternativas. Madrid, 2007. 
En estos casos debe imperar el respeto por las creencias de los distintos usuarios que puedan compartir habitación, debiendo garantizarse la expresión del derecho a la libertad religiosa de cada uno en situaciones de sujeción especial o internamiento por enfermedad.

En la referida STSJ de Cataluña 789/2012, de 27 de junio, la reclamante alegaba precisamente que los usuarios del centro de salud no estaban obligados a soportar la presencia de símbolos religiosos cuando, en el régimen concertado en el que se dispensaba la asistencia, eran los poderes públicos aconfesionales los que la financiaban. La propia doctora y otros profesionales, según se aseguraba, habían mostrado objeciones y requerido la retirada de los símbolos de las zonas comunes del centro de salud, con escaso éxito. El tribunal, que por una parte alude a la desviación procesal para entrar a conocer cuestiones que efectivamente fueron extrañas a la vía administrativa, concluye de manera errónea sobre dichas alegaciones.

Así, pese a reconocer la limitada capacidad de la Administración para retirarlos en tanto las dependencias físicas eran aportadas por el instituto religioso, no admite "que la existencia de algún símbolo religioso católico, confesión a la que pertenece la congregación titular del centro, en zonas comunes pueda vulnerar el código deontológico de su profesión", confundiendo incomprensiblemente el sistema de fuentes, puesto que en ningún momento el recurso invoca las normas deontológicas médicas y sí reiteradamente el art. 16.1 CE y la doctrina constitucional que lo desarrolla.

La percepción es que subsiste en la hermenéutica jurisprudencial cierta confusión en la delimitación y alcance de este tipo de símbolos, que deriva en menoscabo de una pacífica línea común que contribuyera a la resolución segura de la casuística. Como ejemplo de todo ello, la STSJ de Madrid 10166/2010, de 19 enero, desestimó por falta de legitimación activa del recurrente, sin llegar a entrar al fondo del asunto en el que se solicitaba la retirada de una imagen de la Virgen ubicada en las dependencias oficiales del puesto de la Guardia Civil de Almodóvar del Río.

La controversia fue sustanciada definitivamente en la STSJ de Andalucía 272/2011, de 25 febrero, que concluyó en contra de sus pretensiones al considerar que dicho icono mariano trascendía el ámbito de lo puramente religioso para adquirir otra dimensión: histórica, en definitiva. Para el tribunal, «más que de símbolo ostensible o impactante, cabría hablar de un símbolo sin mensaje... o dicho de otro modo, lo que hay es una tradición histórica que supone que la aceptación del empleo del icono mariano no se haga por razones de profesión de culto, 
situándose en un plano donde juegan otros referentes simbólicos y emocionales que no tienen por qué conectar con el hecho religioso en sí mismo considerado... Estamos ante un símbolo en principio religioso que el transcurso del tiempo ha incorporado a otra constelación simbólica, donde la concepción mistérica y sagrada del hijo de Dios queda relegada a un plano ulterior, pasando a primer plano el recordatorio de la Guardia Civil es institución, es decir, sedimento histórico, a la par que realidad actual, alumbrada en un pasado del que no se quiere prescindir, y de que a lo largo del transcurso del tiempo han ido adhiriéndose a su imagen símbolos que expresan con resonancia cultural e histórica más que propiamente confesional».

De conformidad con lo hasta aquí expuesto, no podemos estar de acuerdo con el carácter aséptico, «símbolo sin mensaje», que otorga el tribunal a la imagen de la Virgen. Precisamente porque en este caso el icono transmite explícitamente unos valores religiosos precisos y exactos, la Virgen María como Madre de Dios, que no es posible desligarlo del significado emocional, al que hace referencia la sentencia.

No cabe duda que tendrá valores históricos, y puede que artísticos también, pero no cabe plantearse su significado religioso para cualquier persona, aún de otra convicción, que perciba la imagen en las dependencias públicas.

Cuestión distinta es que el símbolo representado fuera una cruz griega, por ejemplo. Aquí podemos admitir otros significados que, en función del contexto donde se ubique el símbolo, tendrán prioridad sobre el religioso. Así, una cruz griega luminosa de color verde sobre un edificio no indica que se trate de una iglesia, sino más bien de una farmacia; y si es de color azul, probablemente sea un centro sanitario. También es distinto el significado de una cruz griega roja.

En este punto, la jurisprudencia ha estado más precisa. La citada STS 688/1993, de 25 marzo, diferenciaba claramente la cruz del crucifijo, al que no cabe otro significado que el estrictamente religioso. Así, "el crucifijo constituido por una cruz a la que se halla incorporada la imagen de Jesús crucificado y la cruz que según el diccionario de la lengua es la figura formada por dos líneas que se atraviesan y cortan perpendicularmente, o patíbulo formado por un madero hincado verticalmente y atravesado en su parte superior por otro más corto, en los que como suplicio o pena se clavaban o sujetaban las manos y los pies de los condenados a sufrir la muerte por hambre y sed, de manera que, aunque la cruz, sin más, sea un símbolo para los cristianos en memoria de que en una cruz padeció Cristo la muerte, no puede dejar de reconocerse que tiene otras muchas simbologías y no la univoca que corres- 
ponde al crucifijo, por lo que una cruz en sí, no puede sin más, reputarse como objeto sagrado» ${ }^{14}$.

La sentencia del Juzgado de lo Contencioso-Administrativo n. ${ }^{\circ} 3$ de Zaragoza 156/2010, de 30 de abril, también admitió la mayor significación religiosa del crucifijo, que incorpora la imagen de Cristo Crucificado. En la misma se desestimó el recurso de la Asociación MHUEL, Movimiento hacia un Estado Laico contra la petición de retirada de un crucifijo en el salón de Plenos del Ayuntamiento, así como cualesquiera otros símbolos religiosos de dependencias y centros municipales de Zaragoza, en base a la inexistencia de «norma jurídica vigente que prohíba a la Corporación Municipal mantener símbolos de carácter religioso, sobre todo cuando se trate de símbolos con relevante valor histórico y artístico, como sucede en el caso que nos ocupa, no es dable a este juzgador impedir que la voluntad mayoritaria de la misma decida en uno u otro sentido. En definitiva, no concurre el presupuesto básico e imprescindible para que la sentencia pueda estimar la pretensión de la parte recurrente: la inexistencia de una ley que prohíba el comportamiento de la Corporación Municipal» ${ }^{15}$.

Sin entrar en consideraciones, a nuestro juicio extemporáneas sobre el valor histórico o artístico de la simbología religiosa, este pronunciamiento nos parece más acorde con lo hasta aquí expuesto.

En primer lugar porque parece aplicar el principio de proporcionalidad entre los derechos fundamentales en juego y, por otro lado, porque remite al ordenamiento jurídico para implementar soluciones. Es decir, en esta ocasión no existe norma que lo prohíba, permitiendo su presencia en la esfera pública, al igual que los estatutos de la Universidad de Valencia o del Colegio de Abogados de Sevilla, que men-

${ }^{14}$ Aún iría más allá la referida STS 688/1993, de 25 marzo, cuando razonaba que, pese a considerar el carácter religioso del crucifijo, su simbolismo era menos patente si "falta la parte superior del madero vertical en el que suele consignarse la palabra "INRI», compuesta por las iniciales del rótulo latino "Iesus Nazarenus Rex Iuadeorum» que constituye el símbolo de la crucifixión de Cristo y que la distingue de la de cualquier otra persona».

${ }^{15} \mathrm{La}$ asociación recurría los arts. 8.1.a) y 13.1. del Reglamento de Protocolo, Ceremonial, Honores y Distinciones del Ayuntamiento de Zaragoza, así como contra la resolución de la Alcaldía por la que se desestimaba la petición de retirada de un crucifijo colocado en el salón de plenos del Ayuntamiento así como de cualquier otro símbolo religioso que se exhiba en dependencias y centros municipales de Zaragoza. La sentencia razonaba que la petición de retirada de simbología religiosa de todos los centros municipales, podría ir más allá y a título de ejemplo estimaba que ello precisaría retirar la corona con la cruz latina y la cruz de San Jorge del escudo de Aragón, que de este modo, no sería ya el escudo de Aragón. En otro de sus fundamentos confundía, a nuestro juicio, el significado del meritado crucifijo con los valores tradicionales e incluso artísticos que, no cabe duda, debía tener. 
cionábamos con anterioridad, facultaban el patronazgo y advocación mariana. Sin embargo, si en virtud de la reglamentación interna de una administración, institución o ente público, se posibilita su retirada o la decisión es consensuada por la mayoría, ello sería posible ${ }^{16}$.

Ahora bien, para llegar a esta conclusión el juzgador parte de una premisa errónea, porque si le conde al símbolo el significado religioso que efectivamente posee, está claro que debe ser retirado del espacio público puesto que hay precepto constitucional, art. 16.3 CE mediante, que lo avala.

En estos términos, la STSJ de Murcia 948/2009 de 30 octubre, valoró la petición de retirada de un Belén ubicado en el vestíbulo de un centro escolar durante unas navidades. El Tribunal entendió que la ejecución del mismo por parte de los alumnos, además de no constituir discriminación para ningún miembro de la comunidad educati$\mathrm{va}^{17}$, contaba con cobertura normativa suficiente, esto es la Ley Orgánica de Educación, que previene la autonomía de los centros para establecer y organizar actividades culturales escolares y extraescolares. También las SSTSJ de Castilla y León 1617/2007, de 20 septiembre y 3250/2009, de 14 diciembre, que iban más lejos admitiendo la iniciativa y propuesta del afectado, con unas garantías mínimas y seria convicción de atentado a sus creencias religiosas, en la ulterior

${ }^{16}$ Así lo entiende también algún sector de la doctrina al respecto de los comentarios a la STC 130/1991, de 6 de junio, deduciendo que si en el Claustro de la Universidad de Valencia se hubiera votado el mantenimiento del escudo anterior, tal acuerdo no debería considerarse vulnerante del principio de aconfesionalidad del Estado. Alenda Salinas, M. Pineda Marcos, M. La manifestación de religiosidad..., cit.

${ }^{17}$ La STSJ de Murcia 948/2009 de 30 octubre, estimaba, en consecuencia, la inexistencia de derechos fundamentales enfrentados, en los siguiente términos «ni la actividad programada "tunea tu aula en Navidad» con la consiguiente colocación de símbolos religiosos en espacios comunes, viola los derechos fundamentales alegados por el actor (arts. 14, 16 y 24 C. E)... ni la neutralidad del Estado y de las Administraciones debe llegar al extremo de limitar o restringir las libertades o derechos de los ciudadanos, ya que podría darse en ese caso una discriminación negativa, con la consiguiente vulneración del art. 14 C. E. Otra cosa sería que el Estado o la Administración hubiera permitido la realización de determinadas actividades o manifestaciones religiosas a una confesión y a su vez hubiera prohibido las mismas u otras análogas a otras confesiones, lo cual no ha sucedido en el presente caso.... Por el contrario garantiza la libertad ideológica, religiosa y de culto de los ciudadanos y las comunidades sin más limitación, en sus manifestaciones, que la necesaria para el mantenimiento del orden público protegido por la Ley y ello teniendo en cuenta que en este caso los órganos de gobierno del centro no han impedido a miembros de la comunidad educativa la realización de actividades de carácter religioso, por el hecho de profesar una profesión distinta a la católica». Sin perjuicio de estos razonamientos, no está de más recordar que la citada Orden de 3 de noviembre de 1993 le reconoce al Belén carácter de símbolo cristiano, interpretación literal que conllevaría la retirada de la instalación de las zonas comunes del centro. 
decisión del Consejo Escolar, en sendos pronunciamientos en los que se desestimaron la retirada de crucifijos de las aulas ${ }^{18}$.

Para ambos pronunciamientos resulta incontrovertible el significado religioso del crucifijo. En la última de las sentencias señaladas se admite que «la trascendencia religiosa y/o cultural que tiene todo símbolo religioso y el crucifijo en concreto ${ }^{19}$. No reconoce, por el contrario y en esto estamos de acuerdo que, en cualquier circunstancia y lugar «la simple colocación de símbolos religiosos busque ganar prosélitos, siempre que no venga acompañada de un adoctrinamiento explícito más intenso", es decir, no cabe el mero proselitismo impropio. También confiere a la atribución competencial de la Administración la capacidad decisoria ulterior vía potestad reglamentaria, de los centros bajo su gestión, en virtud del principio de autonomía organizativa y de administración económica, eficaz y eficiente, de los recursos públicos.

Sin embargo, en primer lugar, debemos disentir con el razonamiento que se contiene al efecto de la acreditación del efecto perturbador del símbolo ${ }^{20}$. Es la postura que sostiene cierto sector favorable

${ }^{18}$ Aunque principalmente las solicitudes de retirada de crucifijos se ha dado básicamente en el ámbito escolar, sin perjuicio de la citada sentencia del Juzgado de lo Contencioso-Administrativo n. ${ }^{\circ} 3$ de Zaragoza 156/2010, de 30 de abril, existe un precedente en la Resolución de la Dirección General de los Registros y el Notariado, de 12 de junio de 1991, que, sin llegar a entrar al fondo del asunto, se ocupó de la solicitud de retirada de un crucifijo de la sala de un juzgado de primera instancia de Oviedo, donde los recurrentes iban a contraer matrimonio. CAÑAMARES ARRIBAS, Santiago «El Tratamiento de la simbología religiosa en el Derecho Español: propuestas ante la reforma de la Ley Orgánica de Libertad Religiosa». NAVARRO-VALLS y otros (Coords.) La Libertad Religiosa y su regulación legal. Iustel, 2009; p. 536.

${ }^{19} \mathrm{El}$ efecto del crucifijo en el ámbito docente es indudable y este era el fin perseguido, efectivamente, por la Orden dictada el 30 de marzo de 1939, «instaurando el Santo Crucifijo en las Universidades e Institutos de Enseñanza Media», en base a la educación católica, "pues mal se compaginaría la intención de nuestro sistema con el aspecto objetivo de tan importante propósito si no trascendiera a todo aquello que en el orden externo acreditara cumplidamente». BOE n. ${ }^{\circ} 94$, de 4 de abril de 1939.

${ }^{20}$ El Tribunal, tras llegar a la consideración proselitista del crucifijo respecto a los menores sometidos a su presencia en las aulas, argumenta que no habría violación del 16.3 CE si no hay petición concreta de su retirada. Es decir, sólo «en aquellos supuestos en los que medie petición expresa se puede entender existente el conflicto y deberá ceder el derecho de la mayoría, canalizado a través de la decisión escolar de mantenimiento de símbolos religiosos, o deberá ceder el simple hecho de la existencia del símbolo religioso, en beneficio de los derechos del solicitante... Fácil es concluir también que en aquellas dependencias de uso común de los alumnos tales como pasillos, salones de actos, vestuarios, etc., la existencia de petición de retirada implicará también la existencia de conflicto y por lo tanto procederá su retirada, aunque su posible influencia y perturbación sea cuantitativamente menor». Creemos que la sentencia equivoca los términos del conflicto: éste se produce en el ámbito subjetivo del individuo cuando el símbolo presenta varios significados, como hemos visto, pero si previamente se llega 
a mantener las cruces siempre que no entre en cuestión la protección de las minorías que acrediten un interés jurídico en la retirada de las mismas $^{21}$.

$\mathrm{Al}$ respecto, hay que señalar que, conviniendo como parece en el carácter eminentemente religioso del símbolo, del que emana un explícito proselitismo, ya sea por la temprana edad de la persona expuesta a la imagen ya por la forzada situación de especial sujeción, no existe debate: la simbología debe ser retirada en virtud del principio de aconfesionalidad estatal.

En casos extremos, cuando los poderes públicos deban quebrantar de modo excepcional la neutralidad en materia religiosa, deberán motivar la existencia de un interés general prevalente y, en cualquier caso, mantener el equilibrio entre confesiones, ajustando las medidas al principio de igualdad y no discriminación en materia religiosa ${ }^{22}$.

Y ello nos conduce a la segunda de las cuestiones controvertidas. Si efectivamente ambos pronunciamientos coinciden en señalar, con base en la doctrina del TEDH aquí expuesta, que el crucifijo presente en las aulas media en la personalidad en formación, especialmente vulnerable y delicada, a través de una religión en particular, para suponer al Estado más cercano a ésta que otra confesión, o simplemente más próximo al hecho religioso.

Esta circunstancia, lejos de un correcto entendimiento del principio de neutralidad, resulta emocionalmente perturbadora también en situaciones de especial sujeción insertas al ámbito sanitario, en donde

a la valoración que hace el Tribunal del crucifijo, como símbolo religioso y de carácter proselitista, el ámbito objetivo determina que siempre hay conflicto y violación del art. 16.3 CE, por lo que se debe proceder a su retirada.

${ }^{21}$ Para el autor, lo normal será entonces una postura a favor de su mantenimiento, "O al menos $n$ contraria (esto es indiferente)». GonZÁlEZ-VARAS IBÁÑEZ, Santiago. «La polémica sentencia del crucifijo (Resolución del Tribunal Constitucional alemán de 16 de mayo de 1995)». Revista Española de Derecho Constitucional, n. ${ }^{\circ} 47$. Centro de Estudios Políticos y Constitucionales. Madrid, 1996; p. 355.

${ }^{22} \mathrm{La}$ autora considera, en todo caso, que «exigir a las minorías actuar y solicitar la retirada de cualquier símbolo religioso de la esfera pública alegando interés jurídico en ello implica la obligación de declarar sobre sus propias creencias, contenido esencialísimo y primeramente protegido, incluso desde una perspectiva histórica, de la libertad religiosa.. Sería, por tanto, contradictorio e incoherente verse obligado a declarar sobre las propias convicciones, religiosas en este caso, para poder disfrutar de un derecho fundamental a cuyo disfrute se tiene derecho ex constitutione cuando no existe deber jurídico alguno que eludir». PARDo LóPEz, María Magnolia. "Símbolos religiosos y deber de neutralidad estatal: el supuesto de los crucifijos en las aulas como excusa para aproximarse a la relación entre religión y estado». Anales del Derecho, n. ${ }^{\circ} 26$. Universidad de Murcia, 2008. 
cabe reconocer un proselitismo explícito que debería concluir con la retirada de los símbolos religiosos de espacios comunes.

Lejos de tal solución, las STSJ de Castilla y León 3250/2009, de 14 diciembre, articula una suerte de atajo en su propuesta, una solución intermedia en su dicción literal, para solventar los problemas surgidos por la multiculturalidad que nos parece totalmente errónea, pues aboga por mantener, siempre que sea posible, la presencia de símbolos religiosos en ciertos espacios y no en otros. Sin embargo, si queda acreditado el carácter proselitista de los mismos, aun desplazándolos de lugar su efecto será idéntico sobre los expuestos a su presencia, por lo que no cabe otra opción que la retirada definitiva.

En la jurisprudencia comparada europea éste ha sido precisamente el principal caballo de batalla. El posicionamiento del TC Alemán en su sentencia de 16 de Marzo de 1995, no albergaba dudas sobre el carácter específicamente religioso del crucifijo, como símbolo de una religión determinada como es el Cristianismo, y no meramente de la cultura occidental, e iba más allá, al considerarlo símbolo de su expansión misionera ${ }^{23}$. La causa se sostuvo a raíz de la solicitud de retirada de los crucifijos existentes en las aulas de un centro escolar público de Baviera, posicionándose el Tribunal a favor de su retirada. Conforme con el significado objetivo, "misionero», que otorga al símbolo, considera que debe ser retirado por incidir negativamente en

${ }^{23}$ Para el Tribunal Administrativo de Baviera, cuya sentencia fue anulada por el TC Alemán, la cruz no era «la expresión de una confesión de una creencia confesionalmente vinculada, sino un objeto esencial de la tradición cristiana - occidental general y un bien común de este círculo cultural». Sin embargo, el TC Alemán recondujo el significado objetivo de la cruz como símbolo específico y reconocible de la cristiandad: «la cruz es un símbolo de una determinada convicción religiosa y no sólo la expresión de la cultura occidental formada por el Cristianismo... sigue formando parte de los símbolos específicos de la fe del Cristianismo. Es realmente su símbolo de la fe por antonomasia... Sería una profanación de la cruz contraria a la convicción del Cristianismo y de las iglesias cristianas si se la quisiera considerar, como en las sentencias atacadas, como mera expresión de la tradición occidental o símbolo de culto sin referencia especifica de fe. Para el no cristiano o ateo, la cruz se convierte precisamente por el significado que le atribuye el cristianismo y que ha tenido en la historia, en la expresión simbólica de determinadas convicciones religiosas y en símbolo de su expansión misionera». Una interpretación solamente pasiva del crucifijo se rechaza con la siguiente formulación: "tiene un carácter apelativo y representa los contenidos de la fe que simboliza como ventajosos y dignos de seguir». BorowsKI, Martin. "¿Qué significa un crucifijo? Símbolos religiosos y neutralidad estatal». Jornadas sobre La neutralidad del Estado y el papel de la religión en la esfera pública en Alemania. Zaragoza, 20 y 21 de marzo de 2012. Fundación Manuel Giménez Abad de Estudios Parlamentarios y del Estado Autonómico. $w w w$.fundacionmgimenezabad.es/images/Documentos/2012/20120320_epp_borowski_m_es_o.pdf. [Consultado el 6 de septiembre de 2012]. Un pionero comentario a la misma en GoNZÁLEZ-VARAS IBÁNEZ, S. La polémica sentencia del crucifijo..., cit. 
el derecho a la libertad religiosa de quienes quedan expuestos al mismo, máxime al no existir para ello una base legal específica.

Así mismo, estima que el ámbito de especial sujeción en cuyo contexto se ofrece la imagen religiosa, "ciertamente, en una sociedad que deja espacio para las distintas convicciones religiosas, el individuo no tiene derecho a ser salvado de otras manifestaciones de fe, actos de culto o simbolos religiosos. Sin embargo, cabe distinguir esta situación de la creada por el Estado cuando el individuo está expuesto sin posibilidad de escapar a la influencia de una fe en particular, los actos a través de los cuales se manifiesta y los simbolos en los que está presente» ${ }^{24}$.

En cuanto a las alegaciones, mayoritarias, de quienes no resultaron afectados por su carácter proselitista, el Tribunal entendió que la controversia no era encauzable aplicando el principio de la mayoría, puesto que el derecho fundamental a la libertad de creencias protege de un modo especial a las minorías.

De conformidad con lo expuesto al respecto de la acreditación de los damnificados, minoritarios en suma, creemos que las apreciaciones del TC Alemán exceden en este razonamiento, puesto que en el caso que nos ocupa la cuestión no estriba en números, sino en respetar la neutralidad estatal. Pese a que la mayor parte de la doctrina aboga, precisamente, por una resolución del conflicto en términos mayoritarios, como se expone en este trabajo, no podemos estar de acuerdo con este razonamiento, pues si, llegado el caso, se admite la presencia de un símbolo de carácter objetivamente proselitista, éste debe ser retirado sin ningún género de duda.

Cierta corriente razona que la percepción social no apunta hacia una exclusión de la presencia pública de los símbolos religiosos y que es una minoría beligerante la que reclama espacios públicos ideológicamente neutros y asépticos. La laicidad del Estado debe servir de límite a las demandas procedentes de grupos religiosos minoritarios cuya aceptación pudiera hacer peligrar la separación entre lo religioso y lo político, por lo que, en todo caso, deben ser los propios ciudadanos los que determine qué símbolos, nombres o actos públicos prefieren, mayoritariamente ${ }^{25}$.

En esta línea se argumenta que, si bien con base en la Declaración sobre los derechos de las personas pertenecientes a minorías naciona-

${ }^{24}$ Traducción no oficial de la STCF alemán, BVerfGE 93, de 16 mayo 1995.

${ }^{25}$ CASTRo Jover, Adoración. «Inmigración, pluralismo religioso-cultural y educación». Laicidad y libertades: escritos jurídicos, n. ${ }^{\circ}$. Asociación Derecho, Laicidad y Libertades, 2002. 
les o étnicas, religiosas o lingüísticas, aprobada por la Asamblea General de la ONU en 1992, los estados han de procurar que las demandas y legítimas expectativas de las minorías no se vean postergadas injustamente o incluso ninguneadas, lógicamente, serán atendibles en la medida que en cada caso corresponda, debiendo acreditar el interés jurídico invocado para la retirada de los crucifijos o cualquier otro símbolo religioso.

Sin embargo, "los conflictos entre derechos fundamentales (libertad religiosa de los cristianos $v$. libertad ideológica de los no creyentes o libertad religiosa negativa) no pueden ser solucionados en términos de mayorías. Cuando de derechos fundamentales se trata, en general, el criterio de la mayoría es poco o nada operativo, pero no puede ser esgrimido en ningún caso cuando dos derechos fundamentales en concreto están involucrados, libertad religiosa y libertad de expresión, pues éstos son, por definición, derechos de las minorías, derechos reconocidos para proteger a los «disidentes» ${ }^{26}$.

Conformes con este planteamiento, volvemos a reiterar que, si el Tribunal estima el carácter proselitista o misionero, en este caso del símbolo religioso, el pronunciamiento debería ir encaminado a proscribirlo del espacio público en virtud de la conculcación del art. 16.3 CE.

En base a la doctrina del TC Alemán, la STEDH, Caso Lautsi contra Italia, de 3 de noviembre de 2009, también consideró la profunda carga misionera que trasmitía el crucifijo presente en ámbitos de especial sujeción. Si en el Caso Dahlab contra Suiza, como hemos visto, se admitía que el velo islámico era un preeminente «símbolo externo de gran alcance», con capacidad de influir en los menores, en iguales términos y en tanto el significado del crucifijo es indudablemente religioso, «admitido oficialmente por la Iglesia católica que le atribuye un mensaje fundamental», qué duda cabe que la presencia del mismo "puede fácilmente ser interpretada por alumnos de todas las edades como un signo religioso y se sentirán educados en un entorno escolar marcado por una religión concreta. Lo que puede ser estimulante para algunos alumnos religiosos, puede ser emocionalmente perturbador para los alumnos de otras religiones o para aquellos que no profesan ninguna. Este riesgo está particularmente presente en los alumnos pertenecientes a las minorías religiosas. La libertad negativa no se limita a la ausencia de servicios religiosos o de enseñanza religiosa. Se extiende a las prácticas y los símbolos que expresan, en particular o en general,

${ }^{26}$ Prieto Álvarez, Tomás. «Crucifijo y escuela pública tras la sentencia del TEDH Lautsi y otros contra Italia». Revista Española de Derecho Administrativo n. ${ }^{\circ} 150$. Civitas, 2011. 
una creencia, una religión o el ateísmo». El Estado debe de abstenerse de influir, en un grado superior a la masa de ciudadanos, sobre aquellos cuya capacidad crítica aún no ha sido formada ${ }^{27}$.

El TEDH consideraba el significado objetivo del símbolo, pues «sin la sombra de una duda, el crucifijo es un símbolo religioso... (y) el intento de atribuirle una interpretación puramente cultural tiene la connotación de una última línea de defensa desesperada» y, al igual que hiciera el TC alemán, le otorga un indudable carácter de proselitismo activo que, en el ámbito de especial sujeción, adquiere un significado relevante, pues resulta «un sector particularmente sensible toda vez que, en este caso, la facultad de coaccionar del Estado se impone a unas mentes que todavía carecen de capacidad crítica que permita distanciarse del mensaje que se colige de una elección preferente manifestada por el Estado en materia religiosa».

En este punto, la exhibición del símbolo religioso es una restricción incompatible con la neutralidad religiosa en el ejercicio de funciones públicas, consideración que no puede declinar en aras de mayorías $^{28}$.

El pronunciamiento fue rápidamente rebatido por un sector de la doctrina, para quien no era tan evidente el significado objetivamente religioso del crucifijo ${ }^{29} \mathrm{ni}$, aun admitiendo cierto carácter apelativo como hipótesis, era aceptable que los menores se vieran forzados a adherirse a la confesión religiosa representada, no resultando tan evi-

${ }^{27}$ Resulta paradójico que, una gran mayoría de quienes niegan el carácter objetivamente religioso y proselitista de los crucifijos en las aulas, invoquen precisamente el principio de neutralidad estatal en materia religiosa para fundamentar la retirada de la asignatura EpC de los planes de estudio. A nuestro juicio, no cabe partir de idénticos planteamientos para justificar razonamientos opuestos.

${ }_{28}$ «La exhibición de uno o varios símbolos religiosos no puede justificarse ni por la demanda de otros padres que quieren una educación religiosa conforme a sus convicciones ni, como sostiene el Gobierno, por la necesidad de un compromiso necesario con los partidos políticos de inspiración cristiana». STEDH, Caso Lautsi contra Italia, de 3 noviembre 2009.

${ }^{29}$ Para algún autor, la primera imprecisión del TEDH estaría en identificar Estado e Iglesia a través del crucifijo y, a partir de esta confesionalidad, admitir la violación del derecho a la libertad religiosa, pues «cómo es posible imaginar, la confesionalidad entraña mayores riesgos para la libertad religiosa, pero no cabe establecer una equivalencia automática entre ellas. Si así fuera, países como Dinamarca, Grecia, o Reino Unido, estarían incurriendo sistemáticamente en toda suerte de vulneraciones del derecho de libertad religiosa de sus súbditos». CAÑamares ARribas, Santiago. "La Cruz de Estrasburgo. En torno a la Sentencia Lautsi v. Italia, del Tribunal Europeo de Derechos Humanos». Revista General de Derecho Canónico y Derecho Eclesiástico del Estado n. ${ }^{\circ} 22$. Iustel, 2010. 
dente el detrimento de la libertad religiosa o la salud psíquica de los éstos que antojaba el TEDH ${ }^{30}$.

Sobre este aspecto se centran las críticas de CAÑAMARES ARRIBAS que, si bien reconoce que «cuando el símbolo, por su propia naturaleza tenga un significado exclusivamente religioso $(y)$ su presencia en el ámbito público pueda responder a una motivación estrictamente religiosa... se podría estar traspasando los límites de la neutralidad religiosa ${ }^{31}$, no admite en el presente caso este carácter objetivo y vejatorio del crucifijo, sino más bien una percepción subjetiva del mensaje que, en ningún caso puede ampararse en una concreta actuación discriminatoria de los poderes públicos para invocar su retirada ${ }^{32}$.

La escalada de críticas doctrinales al controvertido pronunciamiento avivó el debate político y viceversa. Como afirmó NAVARROVALLS, el inusitado interés desplegado revelaba «que estaba en juego un elemento fundamental de la identidad europea, es decir, uno de sus símbolos más representativos, el crucifijo ${ }^{33}$.

La doctrina del TEDH fue acusada de marcar una concepción y tendencia laicista y unilateral, insinuándose casi como una ley natu-

${ }^{30}$ Además de destacar una notoria falta de estructura en la argumentación del TEDH, esta corriente doctrinal sostiene en identidad de fundamentos las críticas aducidas a la mencionada STC Alemán, no obstante la referencia de la Corte de Estrasburgo era evidente. Para un sector doctrinal, «determinar el contenido simbólico en modo alguno es tan sencillo, tal como pretenden el Tribunal Constitucional Federal alemán y el TEDH. Por supuesto, al crucifijo se le atribuye un contenido específicamente religioso, más concretamente en el ámbito eclesiástico, en un contexto sagrado y litúrgico. Pero atendiendo a su naturaleza, un símbolo no es más que un código que requiere una previa interpretación y dicha interpretación puede ser muy distinta según el contexto». MückL, Stefan. "Crucifijos en las aulas: ¿lesión a los derechos fundamentales». Revista General de Derecho Canónico y Derecho Eclesiástico del Estado n. ${ }^{\circ} 23$, Iustel, 2010.

${ }^{31}$ Cañamares Arribas, S. La Cruz de Estrasburgo..., cit.

${ }^{32}$ Aquí sigue el razonamiento ya esgrimido por el Consejo de Estado italiano en su Parere de 15 de febrero de 2006, previa a la resolución desestimatoria de retirada del crucifijo dictada por el gobierno. El alto órgano consultivo no estimaba, en línea con la corriente doctrinal expuesta, que el significado religioso primara sobre otros agregados por la tradición. CAÑAMARES ARRIBAS, Santiago. "Nuevos desarrollos en materia de simbología religiosa». Revista General de Derecho Canónico y Derecho Eclesiástico del Estado n. ${ }^{\circ}$ 24. Iustel, 2010.

${ }^{33}$ NAVARRo-VALLS, Rafael. "Lautsi contra Lautsi. Simbología religiosa y Tribunal de Derechos Humanos». Zenit, el mundo visto desde Roma. 21 de marzo de 2011. Algún sector se preguntaba si, mediante este pronunciamiento, no se estarían redefiniendo los principios europeos y la laicidad, conquistada en el espacio público y entendido conforme al modelo francés, se extendería a los propios usuarios de ese espacio. Iglesias Berlanga, Marta. "¿Crucifijos en las aulas? Asunto Lautsi vs. Italia (demanda n. ${ }^{\circ}$ 301/06). Sentencia del Tribunal Europeo de Derechos Humanos de 3 de noviembre de 2009». Revista General de Derecho Europeo, n. . 20. Iustel, 2010. 
ral y de exceder el ámbito de actuación jurídico-funcional, poniendo en peligro las tradiciones y la soberanía de los estados miembros y «llevando su decisión a la precaria proximidad de un acto ultra vires... asumiendo el papel de legislador europeo general, al revestir una concreta posición, que desde su punto de vista es correcta y por ello universal», en palabras de MÜCKL, para quien «se ponía en peligro las tradiciones de los Estados miembros y la soberanía de los mismos» ${ }^{34}$. Las expectativas pronto se vieron colmadas en el pronunciamiento de la Gran Sala, vaciando de contenido las conclusiones anteriores ${ }^{35}$.

En este sentido, sin duda los comentarios más censurables a la anterior sentencia partieran el juez Bonello, en el voto particular suscrito en la definitiva STEDH, Caso Lautsi contra Italia, de 18 de marzo de $2011^{36}$. Esta opinión concordante con los razonamientos del Tribunal, en donde quizás se confundían los argumentos jurídicos con las licencias literarias más allá de lo conveniente ${ }^{37}$, era sustancial y radicalmente cercana a los posicionamientos maximalistas comentados, pues para el juez, «ningún tribunal supranacional debe sustituir con sus propios modelos éticos las cualidades que la historia ha impreso a la identidad nacional. Un tribunal de derechos humanos tiene el

${ }^{34}$ «Una única Sala ha puesto en cuestión la autoridad de todo el Tribunal - una autoridad que el TEDH requiere de forma fundamental en otros casos, en los cuales (según el verdadero sentido de las palabras) se encuentran en cuestión violaciones de los derechos fundamentales. Y también la idea de la unificación europea ha sufrido daños adicionales; de esta forma, "Europa» (sin perjuicio de que en este caso no está en juego la actuación de un órgano de la Unión Europea -que por su parte apenas ya es reconocido- sino del Consejo de Europa)». MÜCKL, S. Crucifijos en las aulas.., cit.

${ }^{35}$ No menos apasionante resultó el debate posterior, con posiciones ya fijadas y radicalmente enfrentadas. Curioso resulta, como ejemplo de esto, el debate a tres bandas sostenido por Joseph H. H. WEILER, cuyo alegato en representación de varios estados ante el TEDH se recoge expresamente, Massimo DE LA TORRE y Dionisio LLAMAZARES, en El Cronista del Estado Social y Democrático de Derecho, n. ${ }^{\circ} 27$. Iustel, 2012. pp. 28-42.

${ }^{36}$ En el pronunciamiento de Gran Sala, tras relativizar el significado del crucifijo determinado por la Sala Segunda, se justificó su permanencia en orden a una decisión mayoritaria que, como se expuso, consideramos superada: "por un lado, esta presencia no va asociada a una enseñanza obligatoria del cristianismo. Por otro lado, según las indicaciones del Gobierno, Italia abre paralelamente el espacio escolar a otras religiones. Concretamente, el Gobierno indica que no se prohíbe el uso por los alumnos del velo islámico y otros símbolos y atuendos de connotación religiosa, estando prevista una planificación para facilitar la conciliación de la escolarización y las prácticas religiosas no mayoritarias, el comienzo y el fin del Ramadán "se celebran a menudo" en los colegios y existe la enseñanza religiosa facultativa "para todas las confesiones reconocidas». Por otra parte, no hay nada que indique que las autoridades se muestran intolerantes respecto a los alumnos pertenecientes a otras religiones, los no creyentes o los poseedores de unas convicciones filosóficas no relativas a una religión».

${ }^{37}$ Citando expresamente The Man Who Invented History de John Murray o Requiem por una monja de Willian Faulkner. 
papel de proteger los derechos fundamentales, pero sin perder nunca de vista lo siguiente: las costumbres no son caprichos que pasan. Evolucionan con el tiempo, se solidifican a través de la historia para constituir un cemento cultural. Se convierten en símbolos extremadamente importantes que definen la identidad de las naciones, las tribus, las religiones, los individuos.

No se debe invitar a un tribunal europeo a arruinar siglos de tradición europea... Antes de sumarnos a cualquier cruzada tendente a demonizar el crucifijo, creo que es necesario que volvamos a colocar en su justo contexto histórico la presencia de este símbolo en las escuelas italianas... De hecho, es más bien su ausencia la que sería chocante o sorprendente. William Faulkner dio en el núcleo del problema: el pasado nunca muere. De hecho, ni siquiera es pasado. Nos guste o no, los perfumes y la peste de la historia nos acompañan siempre».

Efectivamente, el pronunciamiento partía del reconocimiento religioso del crucifijo, evidente por otra parte a estas alturas del debate. Si bien, de este carácter objetivo no resulta un proselitismo decidido como pretendía la anterior sentencia, o mesiánico en literalidad del razonamiento alemán. El crucifijo transmitiría un simbolismo esencialmente pasivo, por lo que las intervenciones en los derechos fundamentales y la afección de la neutralidad estatal quedan, si se producen $^{38}$, muy atenuadas, no pudiendo atribuirse una influencia comparable a la que puede tener la estricta evangelización o propaganda religiosa. El juez Power, en su opinión concordante a la propia sentencia, dejó sentado que los símbolos «pueden ser silenciosos al mismo tiempo que parlantes, sin implicar coerción o adoctrinamiento".

Por otro lado y de conformidad con lo expuesto, compartimos el margen de apreciación que la Gran Sala otorga a las autoridades estatales para reglamentar la presencia de símbolos en los espacios públicos, siempre que no impere con carácter objetivo un fuerte proselitismo frente a otros significados que, eventualmente, puedan incluirse en el mismo. En cuyo caso, su presencia resultaría inconstitucional, como se evidenciaba la anterior STEDH, Caso Lautsi contra Italia, de 3 de noviembre de 2009, cuyos razonamientos resultan más estructurados y acordes, en definitiva, con la propia doctrina emanada hasta

${ }^{38} \mathrm{Si}$, pese al carácter pasivo, se admite su significado religioso, cabe plantearse qué ocurre en el ámbito subjetivo, «cuando alguien por su convicción entiende que el crucifijo tiene un carácter apelativo y que, dicho metafóricamente, "le habla» con una tendencia misionera? Esto lo declara la Gran Sala simplemente como imposible o irrelevante. En efecto, el significado como símbolo religioso con carácter apelativo se excluye de antemano de la gama de los significados relevantes». BOROWSKI, M. ¿Qué significa un crucifijo?..., cit. 
el momento de la Corte de Estrasburgo ${ }^{39}$, acogiendo, sospechosamente, las más inmediatas tesis aportadas en la STC Austriaco, de 9 de marzo de 2011, cuando consideró el alcance limitado y pasivo de una cruz presente en un jardín de infancia ${ }^{40}$.

Efectivamente, si en el Caso Dahlab contra Suiza, el TEDH admitió el "poderoso carácter externo» del velo islámico para actuar claramente con fuerza sobre alumnos de entre cuatro y ocho años, la decisiva diferencia de edad en el caso presente, entre ocho y doce, no es justificación suficiente para considerar un grado de madurez en los menores que, por si sola, exima la retirada del crucifijo, al que reconoce no obstante significado religioso ${ }^{41}$.

Aunque tampoco podemos asentir a los extremos que pretende el juez Maliverni en la opinión disidente a que se adhiere la juez Kalaydieva, para quien «la presencia del crucifijo en las escuelas puede lesionar de forma más grave la libertad religiosa y el derecho a la educación de los alumnos que los signos religiosos en el atuendo que puede llevar, por ejemplo, una profesora, como el velo islámico».

El mensaje no puede ser mensurado en términos cualitativos ni cuantitativos, por lo que tratándose de un símbolo dinámico o estático, sí es cierto que, como refiere el mismo voto particular, el impacto que puede tener su presencia «no tiene parangón con el que puede ejercer su exposición en otros establecimientos públicos, como una mesa electoral o un tribunal. En efecto, como señaló la Sala pertinentemente, en los colegios la facultad de coaccionar del Estado se impone a unas mentes que todavía carecen (según el grado de madurez del niño) de capacidad crítica que permita distanciarse del mensaje que se colige de una elección preferente manifestada por el Estado»

${ }^{39}$ Como expone algún autor, "con vistas a la calidad de la argumentación hay que decir que en el caso Lautsi una sentencia argumentada de modo reproducible y probable, fue anulada por una sentencia de la Gran Sala peor argumentada en las cuestiones centrales». BorowsKi, M. ¿Qué significa un crucifijo?..., cit.

${ }^{40}$ Prieto Álvarez, T. Crucifijo y escuela pública..., cit.

${ }^{41}$ En este sentido suscribimos alguna posición crítica. «La Gran Sala solamente afirma que las circunstancias en Dahlab eran completamente distintas. El que espere ahora una argumentación sustancial con las supuestas diferencias entre, por una parte, el velo de una autoridades estatales en Dahlab finalmente habian prohibido el velo no sólo por la edad de los niños escolarizados y que la Corte habia aceptado esto como correspondiente al margen de maniobra del estado miembro. Los niños que estaban afectados en Dahlab tenían entre cuatro y ocho años, mientras que los hijos de la querellante en el caso Lautsi ocho y doce. Que ello represente una diferencia decisiva no es probable y apenas se podrá argumentar profesora y el crucifijo por otra, quedará decepcionado». BorowsKI, M. ¿Qué significa un crucifijo?..., cit. 
La STEDH, Caso Lautsi contra Italia, Gran Sala, de 18 de marzo de 2011, representa a nuestro juicio un paso atrás respecto al valiente pronunciamiento emitido en primera instancia que no favorece, precisamente, la consecución de un marco de tolerancia satisfactorio. A título ilustrativo, la combativa y extensa opinión concordante del juez Bonello, contrario a la retirada de símbolos religiosos, «objetos mudos ${ }^{42}$ los denomina, de la esfera pública, que supondría «una adhesión positiva y agresiva al agnosticismo o la laicidad, y habría sido todo menos un acto neutro. Mantener un símbolo donde siempre ha estado, no es un acto de intolerancia de los creyentes o de los tradicionalistas culturales. Sacarlo de su sitio sería un acto de intolerancia de los agnósticos y los laicos... La mera exposición del testimonio silencioso de un símbolo histórico, que de manera tan indiscutible forma parte del patrimonio europeo, no constituye una "enseñanza", y tampoco conculca gravemente el derecho fundamental de los padres a determinar qué orientación religiosa, en su caso, deberán seguir sus hijos».

Hasta quienes fueron más críticos con el pronunciamiento de la Sala, reconocen que un adecuado entendimiento de la laicidad debe llevar a su conceptuación en términos positivos, lejos no sólo de posicionamientos hostiles sino también de cualquier actitud de indiferencia por parte de los poderes públicos hacia el fenómeno religioso ${ }^{43}$. Como apunta CAÑAMARES ARRIBAS, el principio de neutralidad no implica que el titular de la libertad religiosa, en su vertiente negativa, posea una patente de corso para rechazar cualquier elemento de transcendencia religiosa en el ámbito público ${ }^{44}$, sino que «sólo cuando

${ }^{42}$ Suscribimos aquí la opinión del profesor DE LA TORRE, contrario a esta calificación, y para quien el crucifijo nunca es «un símbolo inocuo, como pretenden algunos blasfemando, ni blasfemando igualmente un símbolo de laicidad. Tanto es así que la "Cruz Roja» (la organización internacional) cambia su símbolo según los países y de las religiones y se hace "media luna roja», etc... Si el crucifijo fuera un símbolo de laicidad o neutral, ¿Por qué no endosarlo durante una ceremonia islámica o judía? ¿Por qué no proponer su exposición (incluso también por Decreto) en las mezquitas y en las sinagogas?» Así mismo, la de LlamaZARES FERNÁNDEZ, para quien el crucifijo es cualquier cosa menos un símbolo neutral, sino más bien y en un contexto pluralista, de división, pues puede tener otros significados, tales como «la intolerancia, el fanatismo y la violencia. Ni las guerras de religión, civiles o entre Estados y las cruentas persecuciones religiosas, ni la inquisición son verdades de ficción; son historia y el crucifijo puede ser percibido también como símbolo de la violencia e intolerancia, sobretodo en quienes leen la historia sin los ojos de la fe cristiana». DE LA TORRE, M. Sueño de una noche... LlamaZARes Fernández, D. De la verdadera tolerancia..., cit.; pp.36 y 39.

${ }^{43}$ Cañamares ArRiBas, S. Los símbolos religiosos..., cit.

${ }^{44}$ Postura extrema defendida por aquellos que estiman inconstitucional la presencia de todo aquel símbolo religioso no secularizado y que produzca confusión con

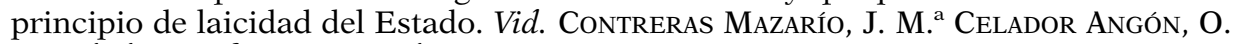
Laicidad, manifestaciones religiosas.., cit. 
la presencia de tales símbolos tenga un carácter proselitista o sean emplazados con una finalidad de presión, entonces se podrá producir la indeseable interferencia con su derecho a la libertad religiosa» ${ }^{45}$.

Con todo y en virtud de una seguridad interpretativa, sería deseable que el TC conociera y entrara al fondo respecto de asuntos como los enjuiciados en las SSTSJ de Castilla y León 1617/2007, de 20 septiembre y 3250/2009, de 14 diciembre, o más decididamente en la desacertada STSJ de Cataluña 789/2012, de 27 de junio, encauzando lo seguros pronunciamientos que surgirán al albur de la confrontación de la simbología religiosa en el espacio público.

\section{CONCLUSIONES}

Aun reconociendo el carácter sagrado de determinados iconos religiosos, hay que descartar que la simple representación de los mismos en un espacio público vaya acompañada de un adoctrinamiento explícito o de un proselitismo intenso. Adoptar posiciones extremas y radicales menoscaba el marco de tolerancia e interrumpe el satisfactorio ejercicio de los derechos fundamentales.

Por otra parte, la función de los poderes públicos como conciliadores de realidad pluriconfesional de nuestra sociedad proscribe el patrocinio de intereses religiosos, aun sustentados en una legítima opinión mayoritaria. Tampoco cabe justificar la supremacía histórica de una u otra confesión para dirimir a su favor aquellos conflictos de conciencia en los que esté en juego el derecho de libertad religiosa de ambas partes, si no que se deben buscar equilibrios y puntos de encuentro que aseguren un tratamiento justo de las minorías desterrando toda clase de prejuicios y de posiciones de dominio.

En definitiva, se debe abogar siempre por un juicio de proporcionalidad y huir del laicismo maximalista. Resulta indudable que, en un país con el secular poso católico como es España, las controversias sobre la innumerable presencia de simbología estática religiosa se funden y confunden con los usos identitarios, por lo que el principal reto de los poderes públicos deberá ir dirigido, como ya expusimos en nuestro anterior trabajo ${ }^{46}$, a la búsqueda de un flexibilización del sistema en la que no se vean alterados los valores constitucionales que asegure un marco de encuentro y tolerancia.

\footnotetext{
${ }^{45}$ Cañamares Arribas, S. El Tratamiento de la simbología religiosa ..., cit; p. 550.

${ }^{46}$ Marabel Matos, J. J. El uso de simbología religiosa dinámica.., cit.
} 
